\title{
Pituitary homeobox 1 (Pitx1) stimulates rat LH $\beta$ gene expression via two functional DNA-regulatory regions
}

\author{
Qiaorong Jiang, Kyeong-Hoon Jeong ${ }^{1}$, Cheryl D Horton² and Lisa M Halvorson \\ Division of Reproductive Endocrinology, Department of Obstetrics and Gynecology, University of Texas Southwestern Medical Center, Dallas, TX 75390-9032, USA \\ ${ }^{1}$ Division of Endocrinology, Diabetes, and Hypertension, Department of Medicine, Brigham and Women's Hospital, Harvard Medical School, Boston, MA 02115, USA \\ ${ }^{2}$ Department of Obstetrics and Gynecology, Tufts-New England Medical Center, Boston, MA 02111, USA
}

(Requests for offprints should be addressed to Lisa M Halvorson; Email: Lisa.Halvorson@UTSouthwestern.edu)

\begin{abstract}
Luteinizing hormone (LH) plays a central role in the reproductive axis, stimulating both gonadal steroid biosynthesis and the development of mature gametes. Over the past decade, significant progress has been made in characterizing the transcription factors and associated DNA-regulatory sites which mediate expression of the LH $\beta$-subunit gene $(\mathrm{LH} \beta)$. One of these factors, pituitary homeobox 1 (Pitx1), has been shown to stimulate LH $\beta$ gene promoter activity, both alone and in synergy with the orphan nuclear receptor, steroidogenic factor-1 (SF-1), and the early growth response gene 1 (Egr-1). Prior reports have attributed the Pitx1 response to a cis-element located at position -101 in the rat $\mathrm{LH} \beta$ gene promoter. While investigating the role of Pitx1 in regulating rat $\mathrm{LH} \beta$ gene expression, we observed a small, but significant, residual Pitx1 response despite mutation or deletion of this site. In the studies presented here, we identify the presence of a second functional Pitx 1 region spanning positions -73 to -52 in the rat $\mathrm{LH} \beta$ gene promoter. Based on electrophoretic mobility shift assay, Pitx1 binds to both the initially described $5^{\prime}$ Pitx 1 site as well as this putative 3'Pitx1 region. In transient transfection analysis, mutation of the LH $\beta-3^{\prime}$ Pitx1 site significantly blunted Pitx1 responsiveness, with elimination of the Pitx1 response in a construct containing mutations in both Pitx 1 cis-elements. We also analyzed the importance of each of these Pitx1 sites for providing functional synergy with SF-1 and with Egr-1. We observed a markedly decreased synergistic response with mutation of the 5'Pitx1 site with further loss following mutation of the 3'Pitx1 site. In contrast, functional interaction between Pitx1 and Egr-1 persisted with mutation of both Pitx1 regions. We conclude that Pitx1 stimulates the rat $\mathrm{LH} \beta$ gene promoter via two Pitx1 DNA-regulatory regions. These results further our understanding of the molecular mechanisms that regulate expression of this critical reproductive gene promoter.
\end{abstract}

Journal of Molecular Endocrinology (2005) 35, 145-158

\section{Introduction}

The gonadotropins, luteinizing hormone $(\mathrm{LH})$ and follicle-stimulating hormone (FSH), are critical modulators of sexual development and reproductive function, acting on the gonads to stimulate both steroidogenesis and gametogenesis. Produced by the gonadotrope subpopulation of the anterior pituitary gland, LH and FSH are heterodimeric glycoproteins composed of a common $\alpha$-subunit linked non-covalently to one of two unique $\beta$-subunits (LH $\beta$ and FSH $\beta$, respectively). These $\beta$-subunits provide the functional specificity that distinguishes LH from FSH via interactions with distinct G-protein-coupled receptors. Biosynthesis of the $\beta$-subunits is believed to be the rate-limiting step in the generation of physiologically active heterodimers.

Over the past decade, substantial progress has been made in the identification of the transcription factors which are required for basal, tissue-specific, and gonadotropin-releasing hormone (GnRH)-activated expression of the LH $\beta$-subunit gene, including steroido- genic factor-1 (SF-1), early growth response gene 1 (Egr-1) and Spl (Halvorson et al. 1996, 1998, Keri \& Nilson 1996, Parker et al. 1996, Wolfe 1999, Kaiser et al. 2000, Zhao et al. 2001). More recent investigations have demonstrated a critical role for the transcription factor pituitary homeobox 1 (Pitxl) in both anterior pituitary development as well as the regulation of a broad array of pituitary-specific genes in the adult (Lamonerie et al. 1996, Lanctot et al. 1997, Drouin et al. 1998, Tremblay et al. 1998, Kurotani et al. 1999, Lanctot et al. 1999, Quirk et al. 2001, Quentien et al. 2002, Zakaria et al. 2002, Jeong et al. 2004).

Pitx1, and the closely related proteins Pitx2 and Pitx3, are members of the bicoid-related homeodomain protein family. During embryonic development, Pitx1 and Pitx2 are expressed in the epithelia of the oral cavity and the first branchial arch, structures which subsequently develop into the anterior pituitary gland, nasopharynx, palate, tongue, and olfactory and dental epithelium. In later development, Pitxl contributes to the differentiation of anterior pituitary lineages through synergism 
with cell-restricted transcription factors such as SF-1 (gonadotropes), Pitl (lactotropes and somatotropes), and bHLH NeuroD1/Panl (corticotropes; Szeto et al. 1999, Tremblay \& Drouin 1999, Tremblay et al. 1999).

Mice homozygous for deletion of the Pitxl gene undergo normal early pituitary organogenesis, perhaps due to the compensatory effects of Pitx2; however, subsequent pituitary development is markedly abnormal. Both mRNA and protein levels of $\mathrm{LH} \beta, \mathrm{FSH} \beta$, and thyroidstimulating hormone $(\mathrm{TSH}) \beta$ are substantially reduced in Pitx1-null animals with a less-marked decrease in glycoprotein $\alpha$-subunit levels (Szeto et al. 1999).

Pitxl expression persists in the adult pituitary gland. Based on analysis of pituitary-derived cell lines, Pitx 1 mRNA and protein are expressed in all pituitary lineages, with particularly high expression levels in cell lines which express the glycoprotein $\alpha$-subunit (i.e. gonadotropes and thyrotropes) (Tremblay et al. 1998, Kurotani et al. 1999). Within gonadotropes, Pitxl has been demonstrated to stimulate expression of the genes that encode the $\alpha$-subunit, LH $\beta, F S H \beta$, and GnRH receptor (Tremblay et al. 1998, Quirk et al. 2001, Zakaria et al. 2002, Jeong et al. 2004). Pitxl-mediated transactivation of the LH $\beta$ gene has been shown to be enhanced in the presence of the orphan nuclear hormone receptor, SF-1, as well as Egr-1 (Tremblay et al. 1998, 1999, Quirk et al. 2001).

We were interested in investigating the effect of Pitx 1 and known transcriptional partners in regulation of the rat LH $\beta$ gene promoter. In early experiments, we observed persistent Pitxl-stimulated promoter activity despite mutation of the previously described Pitx 1 cis-element at position - 101. In the studies reported here, we identify a second region in the proximal rat LH $\beta$ gene promoter which binds Pitxl and confers Pitx1 responsiveness. Furthermore, we characterize the importance of both of these sites for synergy between Pitxl and SF-1 or Egr-1.

\section{Materials and methods}

\section{Plasmids used in transfection studies}

The LH $\beta$ reporter constructs used for these studies contain the $5^{\prime}$-flanking sequence of the rat LH $\beta$ gene and the first $5 \mathrm{bp}$ of the $5^{\prime}$-untranslated region fused to a luciferase reporter gene, pXP2 (Nordeen 1988). 5' deletions were created by subcloning PCR products containing the LH $\beta$ promoter sequences into the pXP2 vector using BamHI/HindIII sites that were introduced by the primers (Kaiser et al. 1998). In a subset of experiments, the LH $\beta$ promoter sequence was excised using BamHI and HindIII restriction enzymes and inserted into pGL3-Basic at BglI/HindIII (Promega, Madison, WI, USA). Mutations were introduced into the LH $\beta$ promoter region using the QuickChange Site-
Directed Mutagenesis Kit (Stratagene, La Jolla, CA, USA).

The mouse Pitx 1 expression vector contains the Pitx 1 open reading frame subcloned into pcDNA3/Amp (Invitrogen, Carlsbad, CA, USA; kindly provided by U B Kaiser, Brigham and Women's Hospital, Boston, MA, USA; Jeong et al. 2004). The SF-1 expression vector contains $2 \cdot 1 \mathrm{~kb}$ of the mouse SF-1 cDNA driven by the cytomegalovirus (GMV) promoter in the vector pCMV5 (provided by K L Parker, Southwestern University School of Medicine, Dallas, TX, USA; Lala et al. 1992).

\section{Transient transfection of cell lines}

Green monkey kidney fibroblasts $(\mathrm{CV}-1)$ and mouse gonadotrope-derived cells (L $\beta$ T2 and $\alpha \mathrm{T} 3-1)$ were maintained in monolayer culture in low-glucose $(\mathrm{CV}-1)$ or high-glucose (L $\beta$ T2) Dulbecco's modified Eagle's medium supplemented with $10 \%(\mathrm{v} / \mathrm{v})$ certified fetal calf serum and $1 \%(\mathrm{v} / \mathrm{v})$ penicillin/streptomycin at $37^{\circ} \mathrm{C}$ in humidified $5 \% \mathrm{CO}_{2} / 95 \%$ air. The immortalized gonadotrope cell lines were generously provided by Dr P L Mellon (University of California, San Diego, CA, USA; Windle et al. 1990, Thomas et al. 1996). Cells were transfected at 50-80\% confluence in 12-well plates using the calcium phosphate precipitation method ( $\mathrm{GV}-1$ cells) or Lipofectamine reagent (L $\beta$ T2 cells; Invitrogen; Sambrook et al. 1989). Cells received $0 \cdot 4 \mu \mathrm{g} /$ well of reporter vector and $0 \cdot 1 \mu \mathrm{g} /$ well of expression vector. Co-transfection with a Rous sarcoma virus (RSV)- $\beta$ galactosidase plasmid allowed correction for differences in transfection efficiency between wells in all experiments. Cells were harvested approximately $48 \mathrm{~h}$ following transfection and the cell extracts analyzed for luciferase activity and $\beta$-galactosidase activity using the GalactoLight assay system (Applied Biosystems, Foster City, CA, USA; Edlund et al. 1985, deWet et al. 1987). Luciferase activity was normalized to the level of $\beta$-galactosidase activity and results calculated as fold-change relative to expression in the control wells. Data are shown as the mean \pm S.E.M. from 3-7 independent experiments.

\section{Electrophoretic mobility shift assay (EMSA)}

The nucleotide sequence of the rat LH $\beta$ gene promoter is based on sequencing data available at GenBank accession number AF020505. Double-stranded oligonucleotide probes were created by $\mathrm{T} 4$ polynucleotide kinase end-labeling with $\left[\gamma_{-}{ }^{32} \mathrm{P}\right] \mathrm{ATP}$ followed by purification over a Quick Spin G-25 Sephadex column (Roche Applied Science, Indianapolis, IN, USA).

The following oligonucleotide sequences were utilized (substituted nucleotides underlined): (5'Pitxl) 5'-AGAG ATTAGTGTCTAGGTTACGCA-3'; (5'Pitx1 M) 5'-AGA ATTCAGTGTCTAGGTTACGCA-3'; (5'SF1-Pitxl) 5'GTTTCTGACGTTGTCTGTCTCGCGCCGAAAGA 
GATTAGTGTCTA-3'; (5'SF1-Pitx1 M) 5'-CTTTCT GACCTTGTCTGTCTCGCCCGCAAAGAATTCAG TGTCTA-3'; (5'SF1 M-Pitx 1) 5'-GTTTGTGAAATTGT CTGTCTCGCGCGCAAAGAGATTAGTGTCTA-3'; (5'SF1 M-Pitx1 M) 5'-CTTTCTGAAATTGTCTGTC TCGCGCGCAAAGAATTCAGTGTCTA-3'; (3'Pitxl) 5'-CGTGTAGCGTCTGCTTAGTGGCCTTGCAA C-3'; (3'Pitx1 MA) CCTGAATTCTCTGGTTAGTG GCGTTGCCAC; (3'Pitxl MB) 5'-CTGTAGCGTCTG AATTCTGGCGTTGCCAC-3'; (3'Pitx1 MC) 5'-CCT GTAGCGTCTGCTTAGTGGAATTCGCAC-3'.

$10 \mu \mathrm{g}$ nuclear protein or $3 \mu \mathrm{g}$ glutathione-Stransferase (GST) or GST-Pitxl were incubated with 60000 c.p.m. oligonucleotide probe in DNA-binding buffer (20 mM Hepes (pH 7.9), $60 \mathrm{mM} \mathrm{KCl,} 5 \mathrm{mM}$ $\mathrm{MgCl}_{2}, 10 \mathrm{mM}$ PMSF, $10 \mathrm{mM}$ dithiothreitol, $1 \mathrm{mg} / \mathrm{ml}$ $\mathrm{BSA}$, and $5 \%(\mathrm{v} / \mathrm{v})$ glycerol). Where indicated, an excess of unlabeled oligonucleotide or $2 \mu \mathrm{l}$ of antisera was added 20 min prior to the addition of labeled probe. Protein-DNA complexes were resolved on a $5 \%$ nondenaturing polyacrylamide gel in $0.5 \times$ Tris/borate/ EDTA buffer and subjected to autoradiography.

The GST-Pitxl plasmid was generated by insertion of the Pitxl cDNA downstream of the GST coding sequence in the pGEX-4T-2 expression vector (Amersham Biosciences Corp, Piscataway, NJ, USA) in the BamHI/NotI sites (construct provided by U B Kaiser; Jeong et al. 2004). This plasmid was introduced into a BL21 bacterial stock followed by induction with isopropyl $\beta$-D-thiogalactosidase to induce expression of the fusion protein, which was purified on a GST-affinity column (Amersham Biosciences Corp).

Nuclear proteins were isolated using NE-PER Nuclear and Cytoplasmic Extraction Reagents and total protein concentration determined by bicinchoninic acid (BCA) protein assay (Pierce, Rockford, IL, USA). In vitro-translated SF-1 was generated from a plasmid containing $2 \cdot 1 \mathrm{~kb}$ pairs of the mouse SF-1 cDNA (provided by Dr K L Parker) using the TNT Coupled Reticulocyte Lysate System (Promega).

The polyclonal Pitxl antibody was generated in rabbits against a peptide corresponding to amino acids 24-52 of mouse Pitx1 conjugated to keyhole limpet hemocyanin (Covance Research, Richmond, CA, USA; provided by UB Kaiser; Zakaria et al. 2002).

To provide quantitation, autoradiographs were photographed using a Kodak digital camera (DC 290) and the net density of signals was evaluated by Kodak 1D Image Analysis software (Eastman Kodak Company, Rochester, NY, USA).

\section{Statistical analysis}

Statistical calculations was performed using the SigmaStat statistical software package (SPSS Science,
Chicago, IL, USA). Data were analyzed for normality followed by calculation of analysis of variance (ANOVA) or the Kruskal-Wallis ANOVA on ranks for nonparametric data. The Student-Newman-Keuls method was utilized for post-hoc comparison, except for experiments with different sample sizes in which case Dunn's test was employed. Statistical significance was set at $P<0 \cdot 05$.

\section{Results}

\section{LH $\beta$ gene expression is activated by Pitx 1 and SF-1 acting alone and in synergy}

We first analyzed the effect of Pitxl and/or SF-1 on transactivation of the LH $\beta$ gene promoter using transient transfection experiments in two cell lines, a gonadotrope-derived cell line (L $\beta$ T2) and a fibroblast cell line $(\mathrm{CV}-1)$. Cells were transfected with a reporter construct containing region $-207 /+5$ of the rat LH $\beta$ gene promoter upstream of the luciferase reporter vector, pXP2. Cells were co-transfected with expression vectors for Pitxl and/or SF-1. In CV-1 cells, which lack both transcription factors, LH $\beta$ gene promoter activity was increased significantly with the addition of Pitxl or SF-1 (17- and 55-fold, respectively; $P<0.05$ versus the empty control vector) (Fig. 1A). The addition of both factors produced a synergistic response of over 110-fold $(P<0.05$ versus control and versus Pitxl or SF-1 alone). In L $\beta$ T2 cells, overexpression of Pitx 1 or SF-1 modestly, but significantly, increased LH $\beta$ promoter activity relative to control wells (1.8- and 2-fold, respectively; $P<0.05$ versus control; Fig. 1B). Once again, a synergistic response was observed with the overexpression of both factors $(7 \cdot 5$-fold; $P<0 \cdot 05$ versus control and versus Pitxl or SF-1 alone). The comparatively small magnitude of the response in the gonadotrope L $\beta$ T2 cell line is likely due to the high level of endogenous Pitx 1 expression reported in these cells. Therefore, in order to increase our ability to identify subtle changes in expression, we chose to continue our analysis in the CV-1 cell line.

\section{Residual Pitx1 response with mutation or deletion of the previously identified Pitx1 element}

We next evaluated the response to Pitxl following deletion or mutation of the previously identified Pitx 1 site (Fig. 2A). A statistically significant residual Pitxl response was observed in the mutated construct (7·6-fold) and in the $5^{\prime}$ deleted constructs $(3 \cdot 6$ - and 2-fold for the $-82 /+5$ and $-68 /+5$ constructs, respectively; $P<0.05$ versus response in the empty reporter vector, pXP2). In order to confirm this observation, additional constructs were generated which contained rat LH $\beta$ 

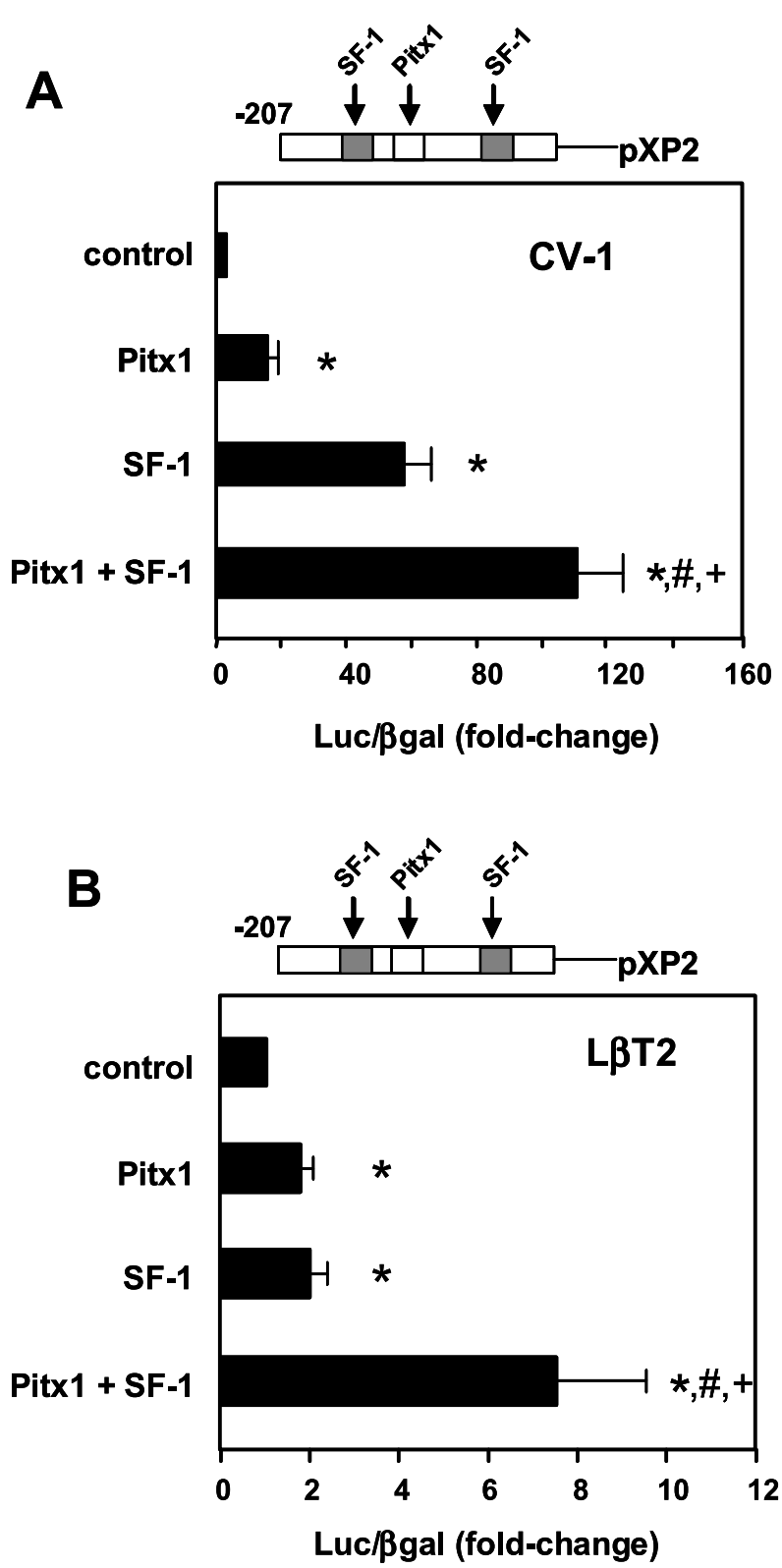

Figure 1 Pitx 1 and SF-1 act alone and in synergy to increase $\mathrm{LH} \beta$ gene promoter activity. Fibroblast CV-1 cells $(A)$ and gonadotrope-derived $L \beta T 2$ cells $(B)$ were transiently transfected with region $-207 /+5$ of the rat $\mathrm{LH} \beta$ gene promoter linked to a luciferase reporter construct, pXP2. Cells were co-transfected with CMV-driven expression vectors encoding Pitx1 and/or $\mathrm{SF}-1$. Control wells received equivalent amounts of 'empty' expression vector. All cells were co-transfected with an RSV- $\beta$-galactosidase vector to control for potential differences in transfection efficiency. Approximately $48 \mathrm{~h}$ after transfection, cells were analyzed for luciferase and $\beta$-galactosidase activity. Luciferase activity was normalized to $\beta$-galactosidase activity and promoter activity was calculated as fold-change over expression in the control wells. ${ }^{*} P<0.05$ versus control, $\# P<0.05$ versus $P$ itx1 alone, $+P<0.05$ versus SF-1 alone. gene sequences in a second luciferase reporter vector, pGL3. As shown in Fig. 2B, a residual Pitxl response was again observed in a construct containing a mutation in the -101 Pitxl site (2·8-fold; $P<0 \cdot 05$ versus control). Taken together, these results suggested strongly the presence of a second functional Pitxl cis-element in the LH $\beta$ gene promoter.

\section{Pitx1 present in gonadotropes binds to the LH $\beta$ gene promoter}

EMSA was used to characterize the site(s) at which Pitx 1 interacts with the rat $\mathrm{LH} \beta$ gene promoter. As shown in Fig. 3A, nuclear extracts from the gonadotrope-derived aT3-1 cell line bound to an oligonucleotide probe which spans the -101 Pitxl cis-element to produce a dominant band (Fig. 3A, lane 1). Formation of this complex was effectively competed by the addition of excess cold wild-type oligonucleotide (Fig. 3A, lane 2), but not by a mutated oligonucleotide (Fig. 3A, lane 3) or by an unrelated oligonucleotide containing the LH $\beta$ 3'Egr-1 site (Fig. 3A, lane 4). Gonadotrope nuclear extract interacted weakly with the mutated oligonucleotide when used as a probe, demonstrating specificity of the protein-DNA interaction (Fig. 3A, lane 5).

The identity of the dominant band was confirmed by the addition of a Pitxl-specific antiserum which blunted the Pitx1-containing complex (Fig. 3B, lanes 1 and 2). In contrast, a pre-immune antibody had no effect on this complex (Fig. 3B, lane 3). Nuclear extract from the differentiated L $\beta$ T2 cell line was also demonstrated to contain endogenous Pitxl which bound to the LH $\beta$ 5'Pitxl region (Fig. 3B, lanes 5 and 6).

\section{Pitx1 binds to a second proximal site in the rat LH $\beta$ gene promoter}

Analysis of the proximal rat LH $\beta$ gene promoter sequence identified three regions with homology to the consensus Pitxl cis-element (TAA(T/G)CG). These putative cis-elements within the $3^{\prime} \mathrm{Pitx} 1$ region were designated sites A, B and C (Fig. 4). As shown in Fig. 5A, a GST-Pitxl fusion protein bound with high affinity to the previously identified 5'Pitxl site on EMSA (Fig. 5A, left-hand panel). This complex was effectively supershifted by a Pitxl-specific antibody. Pitxl also bound specifically to an oligonucleotide probe which spans all three putative $3^{\prime}$ Pitxl sites in the $3^{\prime}$ Pitxl region (Fig. 5A, right-hand panel).

\section{Comparison of Pitx1 affinity for the 5'Pitx1 and 3'Pitx1 regions}

Pitxl was noted to produce a less-intense complex with the $3^{\prime}$ Pitxl probe than with the probe spanning the 


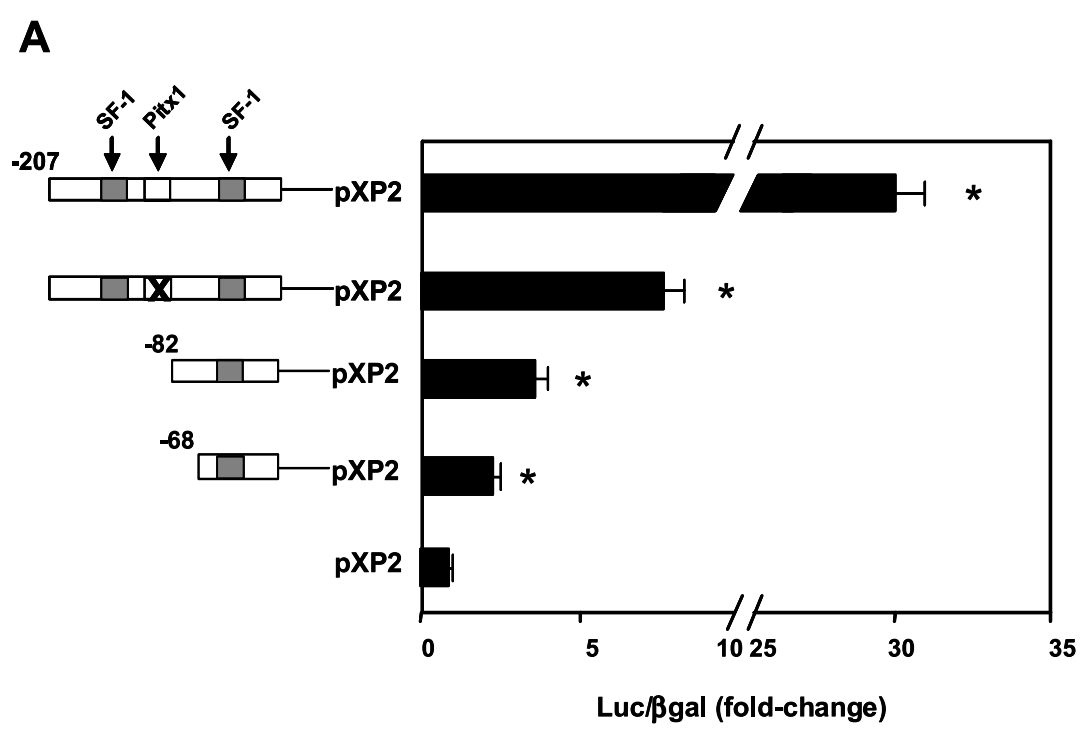

B

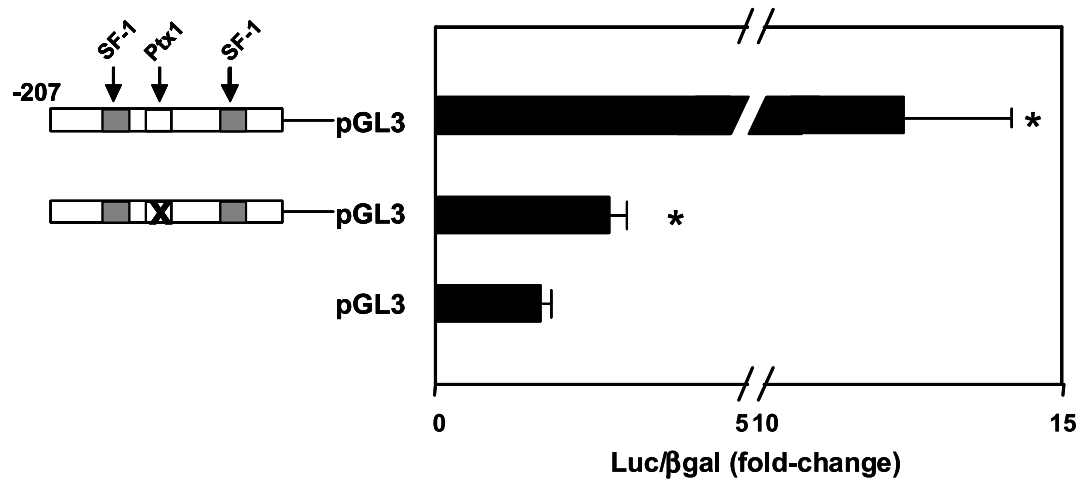

Figure 2 Identification of a residual Pitx1 response following mutation or deletion of the -101 Pitx1 cis-element. CV-1 cells were transfected with the indicated luciferase reporter construct and a Pitx1 expression vector or empty expression vector. Cells were harvested and results calculated as described in Fig. 1. (A) CV-1 cells were transfected with luciferase constructs containing region $-207 /+5$ of the rat $\mathrm{LH} \beta$ gene promoter present as the wild-type or with mutation in the previously identified Pitx1 cis-element at position -101. Alternative wells were transfected with $5^{\prime}$ deleted $\mathrm{LH} \beta$ promoter constructs or with the empty reporter vector, $\mathrm{pXP} 2 .{ }^{*} P<0.05$ versus Pitx1 response in pXP2. (B) CV-1 cells were transfected with reporter constructs containing region $-207 /+5$ of the wild-type or Pitx 1 -mutated rat $\mathrm{LH} \beta$ gene promoter linked to the luciferase reporter vector, pGL3. ${ }^{*} P<0.05$ versus $P i t x 1$ response in pGL3.

more distal Pitxl cis-element. In order to estimate the relative efficiency of the Pitx 1-DNA interaction in these two regions, a competitive EMSA experiment was performed (Fig. 5B). Pitxl fusion protein was added to the oligonucleotide probe containing the $3^{\prime}$ Pitxl region. Increasing amounts of unlabeled $5^{\prime}$ or $3^{\prime}$ Pitxl oligonucleotide were added and the intensity of the generated complex quantified. Based on results from three independent experiments, the Pitxl binds the 5'Pitxl site with approximately 6 -fold greater affinity than the
3'Pitx 1 region. This result is consistent with the relative functional importance of these two sites as assessed in transfection experiments.

\section{Pitx1 binds with greatest intensity to site $B$ within the putative $3^{\prime}$ Pitx 1 region of the proximal $\mathrm{LH} \beta$ gene}

We next evaluated the ability of Pitx 1 to bind to each of the putative $3^{\prime}$ Pitxl DNA-binding sites identified in the 


\section{$\alpha$ T3-1 nuclear extract}

A

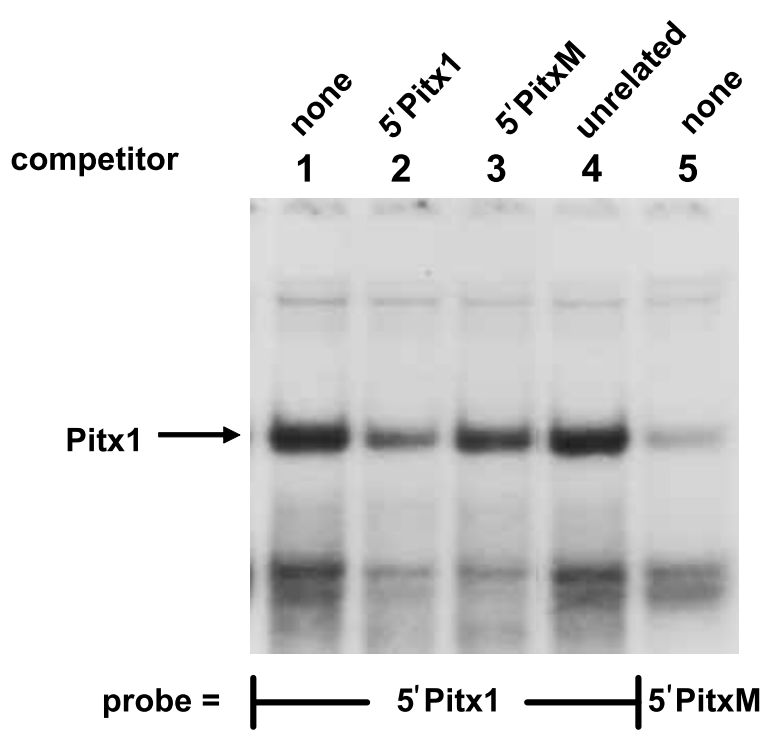

B

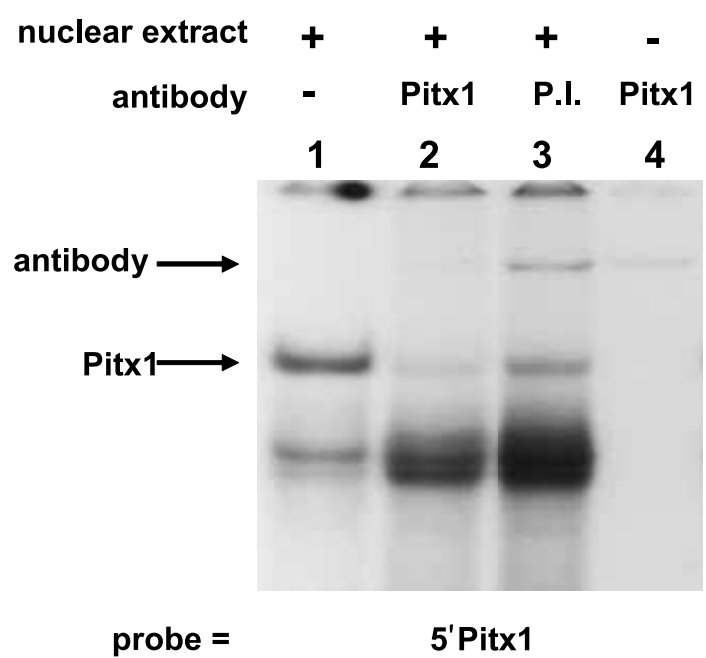

LBT2 nuclear extract

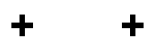

- Pitx1

56

Figure 3 Endogenous Pitx 1 in gonadotrope cell lines binds to the LH $\beta$ gene promoter. Nuclear extracts from $\alpha \mathrm{T} 3-1$ or L $\beta \mathrm{T} 2$ gonadotrope cells were incubated with ${ }^{32} \mathrm{P}$-labeled oligonucleotide probes and the reaction mixture run on a $5 \%$ non-denaturing polyacrylamide gel, dried, and subjected to autoradiography. (A) $\alpha$ T3-1 nuclear extract was added to a ${ }^{32}$ P-labeled oligonucleotide probe spanning region $-103 /-80$ of the rat LH $\beta$ gene promoter as the wild-type sequence (lanes 1-4) or with a mutation in the -101 Pitx1 (5'Pitx1) site (lane 5). Where indicated, a 500-fold excess of wild-type, 5'Pitx1-mutated, or unrelated unlabeled oligonucleotide was added to the reaction mixture (lanes 2, 3, and 4 respectively). (B) $\alpha$ T3-1 (lanes 1-3) or L $\beta$ T2 nuclear extract (lanes 5 and 6 ) were added to the wild-type $5^{\prime}$ Pitx1 probe. As indicated, a Pitx1-specific antibody or a pre-immune antibody (P.I.) was added 20 min prior to the addition of probe. In lane 4, Pitx1 antibody was added to probe without extract. 


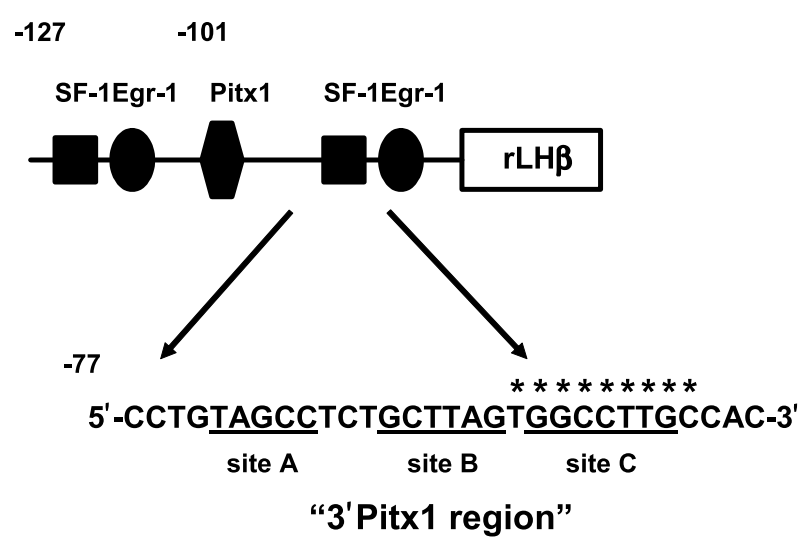

Figure 4 Schematic of the proximal rat LH $\beta$ gene promoter sequence indicating DNA-regulatory elements for SF-1, Egr-1, and Pitx1. By sequence analysis, region -77 to -48 contains three sites with homology to the consensus Pitx1 cis-element. These putative cis-elements are named $3^{\prime} P$ itx 1 sites A, B, and C. Note that the putative $3^{\prime}$ Pitx $1 \mathrm{C}$ overlaps the $3^{\prime} \mathrm{SF}-1$-binding site (TGGCCTTGC).

rat LH $\beta$ gene promoter. Oligonucleotide probes were generated which contained mutations in each of these Pitx1 sites individually. As shown in Fig. 6A, mutation of site B essentially eliminated the ability of Pitxl to bind to the probe. In contrast, substantial amounts of protein binding persisted following mutation of the $\mathrm{A}$ or $\mathrm{C}$ sites. The numerical data presented are based on the cumulative results from four assays, with binding to the wild-type probe set at $100 \%$. Of interest, binding to site A was somewhat decreased in the experiment shown in this figure, raising the possibility that it may contribute to Pitxl effects.

The mutated oligonucleotides were also tested in competition experiments. Due to the relative subtlety of these differences by visual analysis, this experiment was repeated three times and the intensity of the complexes formed quantified. These data were pooled and expressed as a percentage of the 'no competition' control band. As shown in Fig. 6B, excess oligonucleotide containing either the wild-type sequence or a mutation in site $\mathrm{A}$ or site $\mathrm{C}$ decreased complex formation between Pitxl protein and the wild-type $3{ }^{\prime} \mathrm{Pitx} 1$ probe by approximately $30-50 \%$. In contrast, the site B mutant oligonucleotide was unable to compete for Pitxl binding. Taken together, these EMSA data demonstrate the ability of Pitxl to bind to site B located at position $-66 /-60$ in the rat LH $\beta$ gene promoter.

\section{The 3'Pitx1 region contributes to Pitx1-induced activation of the rat LH $\beta$ gene}

In order to test the functional importance of site $\mathrm{B}$, additional luciferase reporter constructs were generated which contained mutations in this site, either alone or
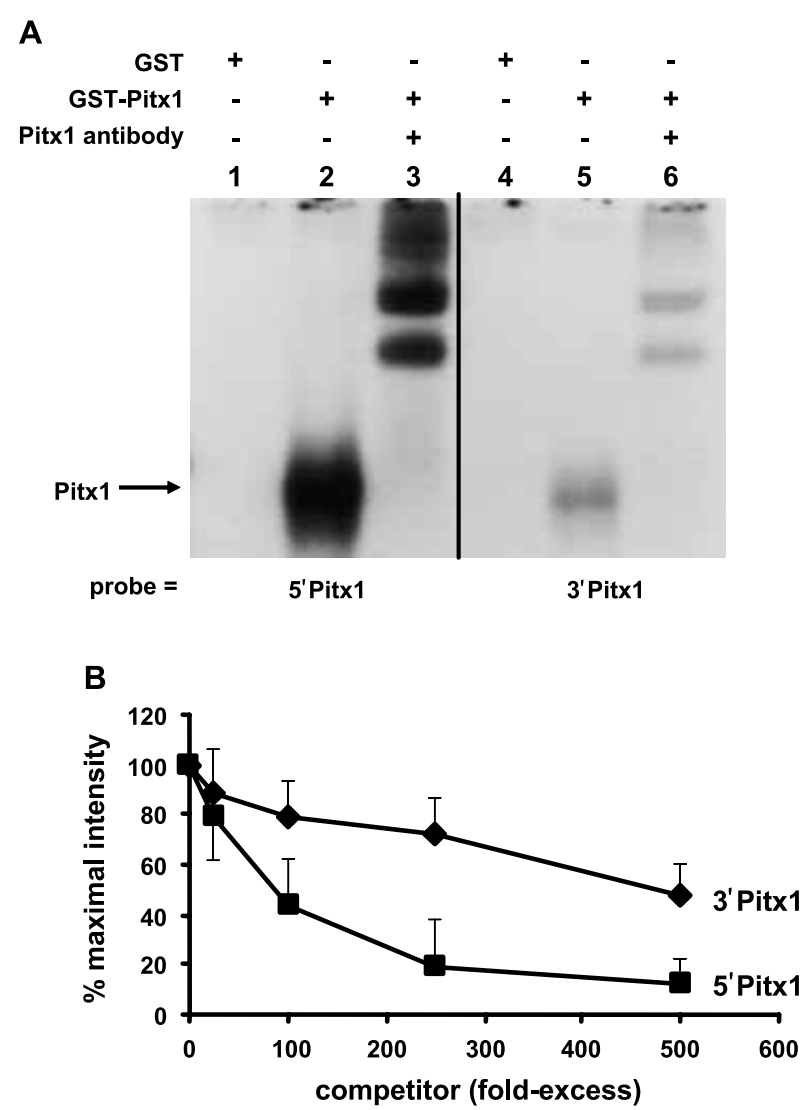

Figure 5 Pitx 1 binds to the $3^{\prime} P i t x 1$ region in the $L H \beta$ gene promoter. (A) GST-Pitx1 fusion protein was added to ${ }^{32} \mathrm{P}$-labeled oligonucleotide probes spanning the 5'Pitx 1 or 3'Pitx1 regions. A Pitx1-specific antibody was added as described in Fig. 3 (lanes 3 and 6). (B) The 3'Pitx1 probe was mixed with GST-Pitx1 and increasing amounts of $3^{\prime} P i t x 1$ or 5'Pitx1 oligonucleotide. The intensity of the resulting complexes was quantified with the mean \pm S.E.M. from three experiments shown.

in conjunction with the mutated 5'Pitxl cis-element. As shown in Fig. 7A, mutation of site $\mathrm{B}$ in the 3 'Pitxl region significantly blunted the Pitxl response in the rat LH $\beta$ gene promoter, with complete loss of Pitx1-responsiveness in the presence of the double mutation.

Functional analysis of the role of site $\mathrm{A}$ was determined by $5^{\prime}$ truncation as already shown in Fig. $2 \mathrm{~A}$, with deletion of this site occurring with $5^{\prime}$ truncation from position -82 to -68 . The Pitxl response decreased from $3 \cdot 6$-fold in the presence of the complete $3^{\prime}$ region to $2 \cdot 0$-fold in the shorter construct $(P<0 \cdot 05$ for construct $-82 /+5$ versus $-68 /+5)$, suggesting that site A may contribute to the Pitxl response in the presence of an intact site $\mathrm{B}$.

We also were interested in investigating the role of each of the Pitxl cis-elements in mediating the synergistic response with SF-1 (Fig. 7B). The addition of 


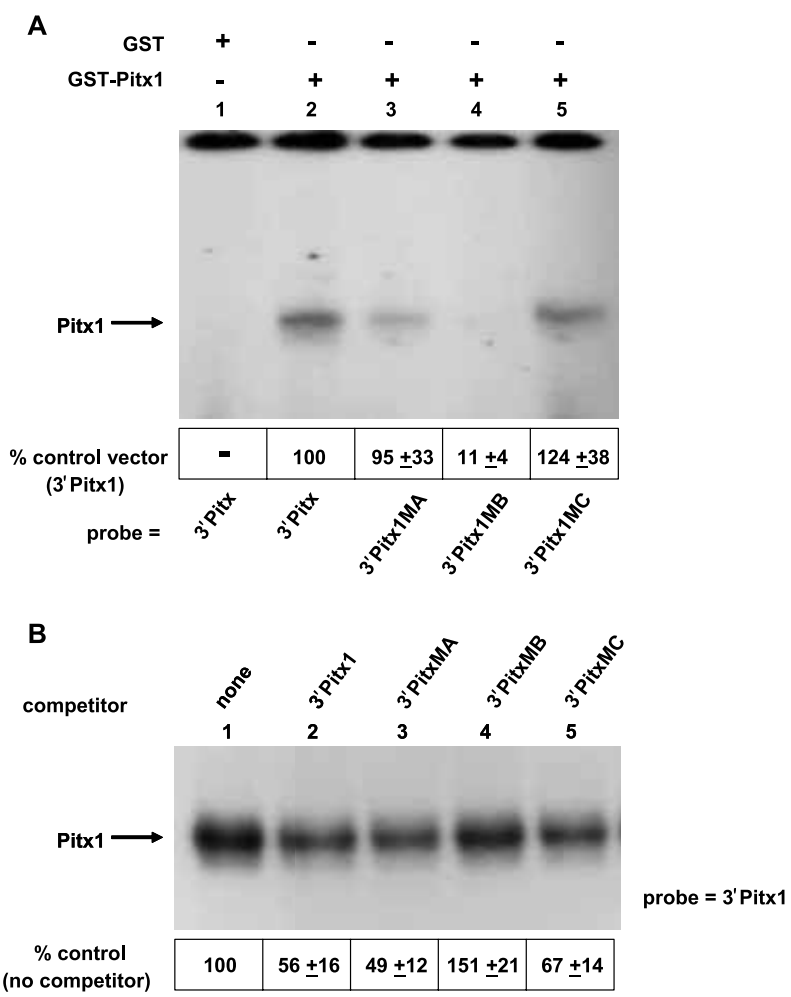

Figure 6 Pitx 1 binds to site $B$ within the $3^{\prime} P$ itx 1 region. (A) GST-Pitx1 protein was added to ${ }^{32} \mathrm{P}$-labeled oligonucleotide probes spanning the $3^{\prime} P$ itx 1 regions as the wild-type sequence or with mutation in putative sites $\mathrm{A}, \mathrm{B}$, or $\mathrm{C}$. The intensity of the resulting complexes was quantified and results expressed as a percentage of binding to the wild-type probe $(n=4)$. (B) GST-Pitx1 protein was added to the $3^{\prime}$ Pitx 1 probe. 500 -fold excess of wild-type or mutated 3'Pitx1 oligonucleotide was added as indicated. Results from three independent experiments were quantified and results expressed as the percentage intensity of the control band (i.e. no competitor).

both Pitx 1 and SF-1 increased luciferase activity by over 100 -fold in the wild-type rat LH $\beta$ gene promoter. In the 5'Pitxl-mutated construct, transfection of Pitxl and SF-1 produced a response that was greater than additive for the two factors alone (5-, 17-, and 43-fold for Pitx1, SF-1, and Pitx 1+SF-1, respectively), but was diminished relative to the wild-type promoter. Mutation of the 3'Pitxl cis-element had minimal impact on the synergistic response.

As an alternative method for analyzing the degree of synergy in the various constructs, the results were also calculated as the response to both transcription factors relative to the response to SF-1 alone. As shown in Fig. 7C, Pitx1-SF-1 synergy was decreased markedly with mutation of the 5'Pitxl site in this series of experiments. Pitxl augmentation of the SF-1 response was unchanged with mutation of the $3^{\prime} \mathrm{Pitx} 1$ site alone; however, synergy was eliminated with mutation of both Pitxl cis-elements suggesting that the 3'Pitxl site may
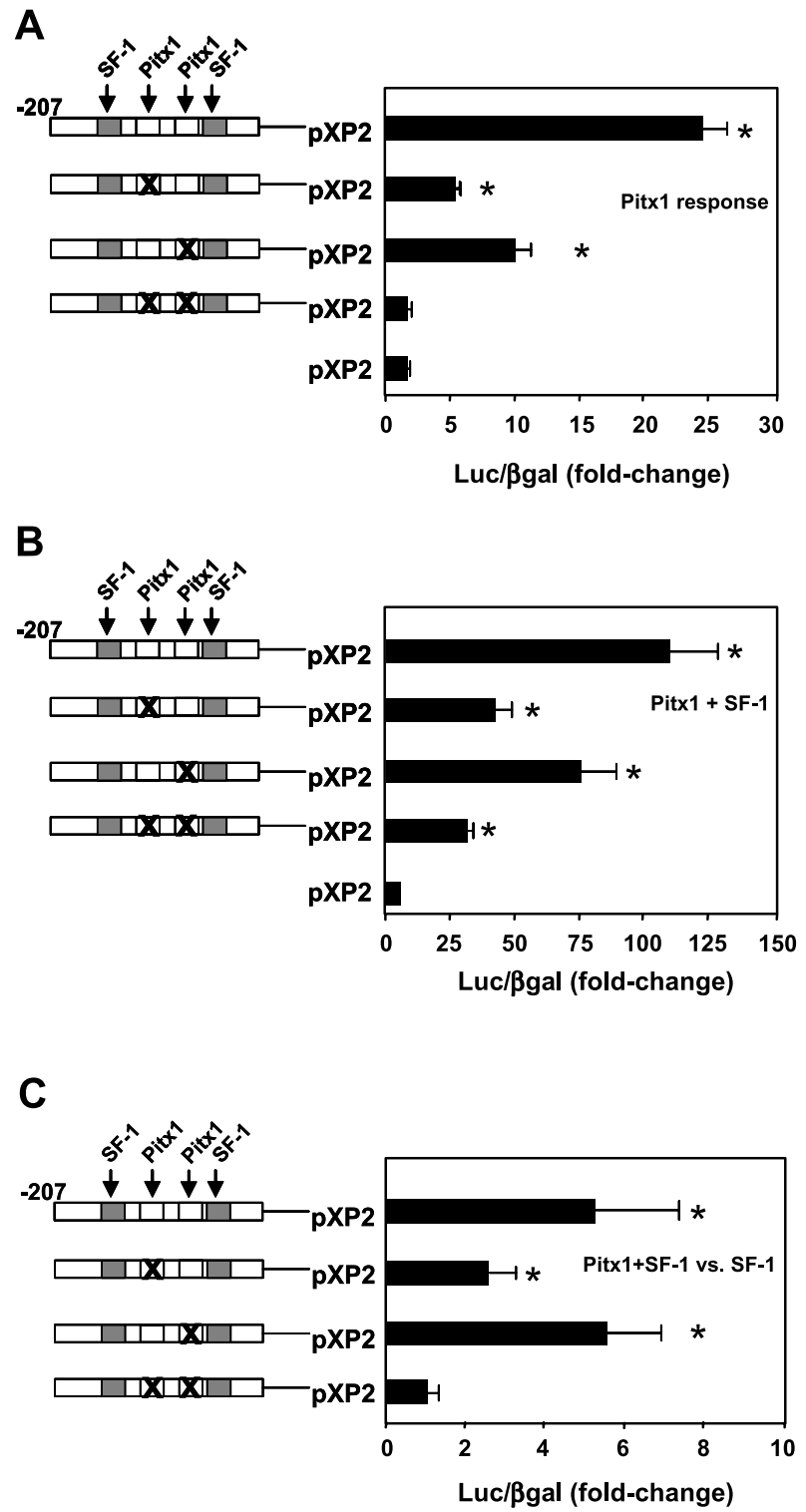

Figure 7 Effect of mutation of the Pitx1 sites on the Pitx1 response and Pitx1-SF-1 synergy. CV-1 cells were transiently transfected with the $-207 /+5 \mathrm{LH} \beta$ gene promoter present as wild-type or with mutation in the 5'Pitx1 cis-element, 3'Pitx1B cis-element, or both. Cells were co-transfected with the Pitx1 and/or SF-1 expression vectors. Cell extracts were harvested and assayed as described in Fig. 1. (A) Analysis of the Pitx1 response. Results shown as promoter activity in response to the Pitx1 expression vector relative to promoter activity with addition of the control expression vector. ${ }^{*} P<0.05$ versus the response in $\mathrm{pXP2}$. (B) Analysis of Pitx1-SF-1 synergy. Results shown as corrected luciferase activity in response to the Pitx1 and SF-1 expression vectors relative to luciferase activity with addition of the control expression vector. ${ }^{*} P<0.05$ versus the response in $\mathrm{pXP} 2$. (C) LH $\beta$ gene promoter activity in response to Pitx1 and SF-1 together relative to addition of SF-1 alone. ${ }^{\star} P<0.05$ for the response to SF-1+Pitx1 versus response to SF-1 alone. 


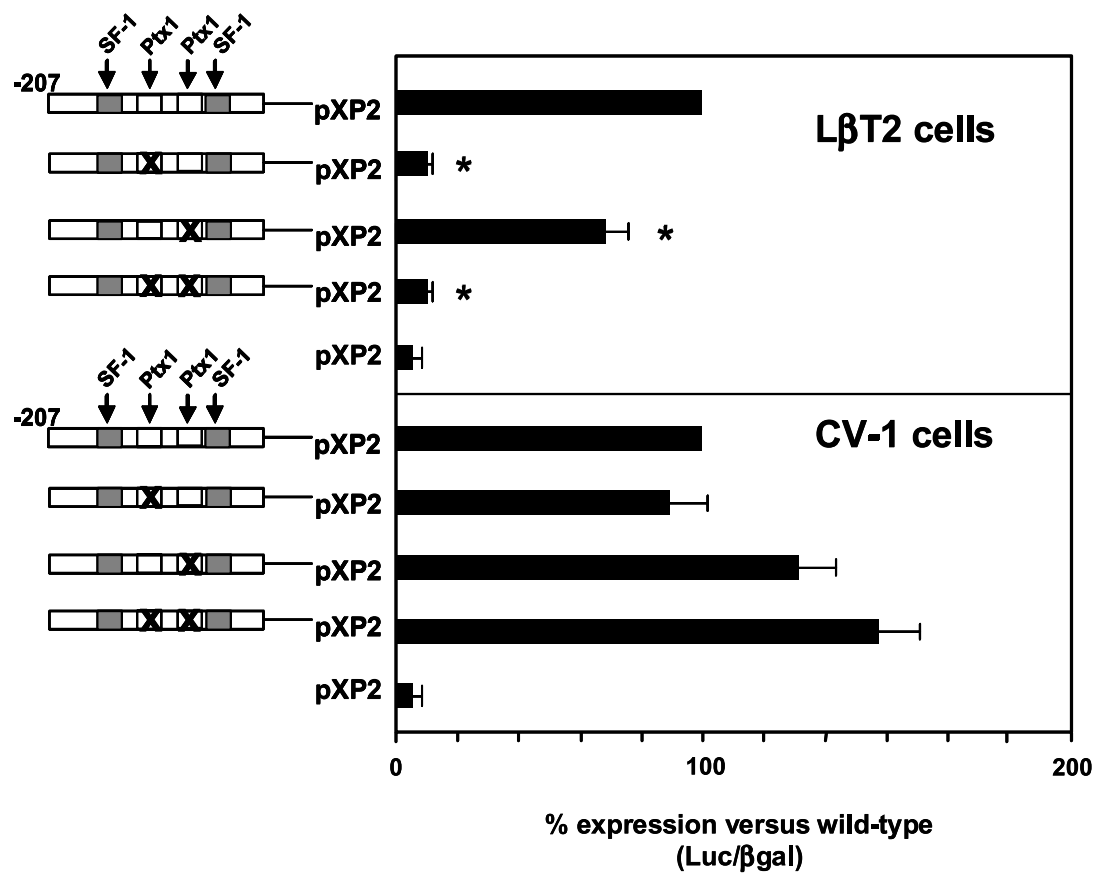

Figure 8 Mutation of the Pitx1 sites blunts rat LH $\beta$ promoter expression in the gonadotrope L $\beta$ T2 cell line. L $\beta$ T2 cells (upper panel) or CV-1 cells (lower panel) were transiently transfected with region $-207 /+5$ of the rat LH $\beta$ gene promoter linked to a luciferase reporter construct, pXP2, present as the wild-type or with mutations in the putative $5^{\prime}$ or $3^{\prime} \mathrm{Pitx} 1$ sites or both. Cells were analyzed for reporter activity approximately $48 \mathrm{~h}$ after transfection. The data shown represent three independent experiments with expression in the wild-type construct set at $100 \%$. ${ }^{*} P<0.005$ versus wild-type for all mutant constructs.

play a minor role in the interaction between SF-1 and Pitxl.

The importance of the 3 'Pitxl site was also evaluated in the gonadotrope L $\beta$ T2 cell line. As shown in Fig. 8 (upper panel), mutation of the putative $3^{\prime}$ Pitxl site blunted LH $\beta$-driven luciferase activity in L $\beta$ T2 cells, although not to the extent observed with mutation of the $5^{\prime}$ site $(P<0.005$ versus wild-type for all mutant constructs). This result is consistent with an inability of endogenous Pitxl to transactivate the mutated sequences. Quirk and colleagues (2001) similarly have shown that mutation of the 5'Pitxl element blocks activation of the bovine LH $\beta$ promoter in L $\beta$ T2 cells. Our interpretation of these data is further supported by equivalent analysis in Pitx l-deficient CV-1 cells in which mutation of the Pitx 1 sites did not blunt basal expression (Fig. 8, lower panel).

\section{Evidence that Pitx1 and SF-1 bind simultaneously to the $5^{\prime}$ Pitx 1 region but not to the $3^{\prime}$ Pitx 1 region}

Our transfection data demonstrated that the 5'Pitx 1 site is more important than the $3^{\prime} \mathrm{Pitx} l$ site in conferring transcriptional synergy by Pitxl and SF-1. We investigated whether this differential response could be explained by differences in the ability of SF-1 and Pitx 1 to bind simultaneously to adjacent Pitxl and SF-1 cis-elements.

As shown on the left-hand side of Fig. 9A, SF-1 and Pitxl bound independently to a probe spanning the 5'SF-1 and 5'Pitxl cis-elements (Fig. 9A, lanes 2 and 4, respectively). A third, larger complex was generated with the addition of both proteins together (Fig. 9A, lane 5), suggesting concurrent binding of SF-1 and Pitxl to this DNA region. This result cannot distinguish direct DNA binding by both factors from DNA binding by a single factor that has formed a complex with a non-DNA binding partner. To further investigate this issue, oligonucleotide probes were utilized which contained mutations in the Pitxl region (Fig. 9A, lanes 6-10), or in the SF-1 site (Fig. 9B, lanes 1-5), or in both sites (Fig. 9B, lanes 6-10). Mutation of the 5'Pitxl region maintained SF-1 binding (Fig. 9A, lane 7) but nearly eliminated Pitxl binding (Fig. 9A, lane 9), whereas mutation of the 5'SF-1 site had the converse effect (Fig. 9B, lanes 2 and 4). No evidence of a higher-order 


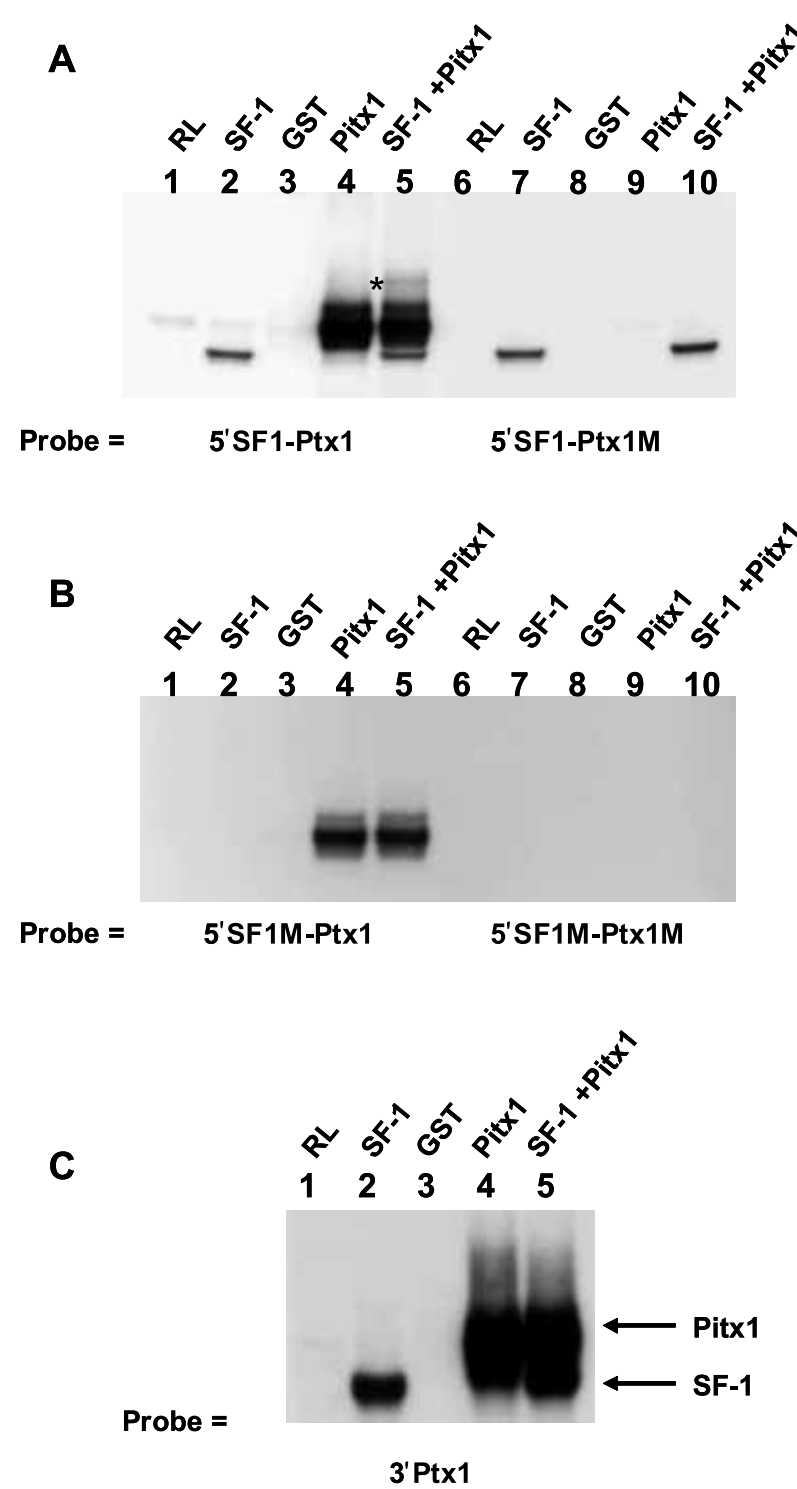

Figure 9 SF-1 and Pitx 1 bind simultaneously to the 5'SF1-Pitx1 region but not to the 3'SF1-Pitx1 region. EMSA was utilized to evaluate the ability of Pitx 1 and SF-1 to bind to the $5^{\prime}$ and $3^{\prime}$ SF1-Pitx1 regions. (A) Pitx1 fusion protein and in vitro-translated SF-1 were added alone (lanes 2 and 4 ) or in combination (lane 5) to an oligonucleotide probe spanning the 5'Pitx1 and 5'SF-1 sites (left panel). * Indicates complex containing both SF-1 and Pitx1. Mutation of the Pitx1 site prevented binding by Pitx1 either alone (lane 9) or in the presence of SF-1 (lane 10). (B) SF-1 (lanes 2 and 7) and Pitx1 (lanes 4 and 9) were added to a probe containing a mutation in the $5^{\prime}$ SF-1 site (left) or in both the $5^{\prime}$ SF-1 and 5'Pitx 1 sites (right). SF-1 and Pitx1 were added in combination in lanes 5 and 10. (C) SF-1 (lane 2) and Pitx1 (lane 4) bind to a probe spanning the $3^{\prime}$ SF-1 and $3^{\prime} P i t x 1$ sites. No additional complexes were noted in the presence of both proteins (lane 5). $R L$, reticulocyte lysate. complex was observed with either of the mutated probes, arguing against the ability of either SF-1 or Pitx 1 to bind indirectly to the $5^{\prime}$ region.

In Fig. 9C, we investigated the ability of Pitxl and SF-1 to bind to an oligonucleotide probe spanning the 3'SF-1 and Pitxl sites (probe $3^{\prime}$ Pitx 1 ). In contrast to the results obtained with the $5^{\prime}$ region, we did not observe cooperative binding to the $3^{\prime}$ region (Fig. 9C, lane 5). In conjunction with the transfection data, these results are consistent with a model in which DNA binding at adjacent Pitxl and SF-1 sites, as occurs in the $5^{\prime}$ region of the LH $\beta$ gene, is important for functional synergy between these two transcription factors.

\section{Both Pitx1 regions contribute to synergy with Egr-1 on LH $\beta$ gene expression}

Previous reports have demonstrated functional synergy between Pitxl and Egr-1, an immediate early gene which is highly induced by GnRH. Our group and others have characterized two Egr-1 cis-elements in the LH $\beta$ gene promoter located near the SF-1 and Pitxl sites (Halvorson et al. 1998, 1999, Dorn et al. 1999, Tremblay \& Drouin 1999, Wolfe \& Call 1999). We investigated the importance of the two Pitxl DNAregulatory regions in conferring functional synergy using transfection experiments that paralleled those shown for Pitxl and SF-1 in Fig. 7. As demonstrated previously, Pitxl and Egr-1 interact cooperatively to stimulate LH $\beta$ gene promoter activity (Fig. 10A). Next, the response to Pitxl and Egr-1 together was evaluated in the wild-type and Pitxl mutation constructs (Fig. 10B). Mutation of the $5^{\prime}$ and/or $3^{\prime}$ Pitxl regions significantly decreased the Pitx 1-Egr-1 response relative to the wild-type promoter sequence $(P<0 \cdot 05)$, consistent with a contribution by both regions to this response. Interestingly, the response to both transcription factors exceeded the response to either transcription factor alone in the double mutant construct (Fig. 10B and C). This result suggests that Pitx1-Egr-1 synergy does not require binding by Pitxl, unlike the result observed for the Pitx1-SF-1 interaction.

\section{Discussion}

Regulation of gonadotropin biosynthesis and secretion is a critical step in the maintenance of normal reproductive function in both males and females. Investigations from a number of laboratories have begun to elucidate the complex interactions which mediate expression of the LH $\beta$ gene. In vivo and in vitro experiments have established a role for the homeobox gene product, Pitx1, in mediating $\mathrm{LH} \beta$ promoter activity, both alone and in 
A

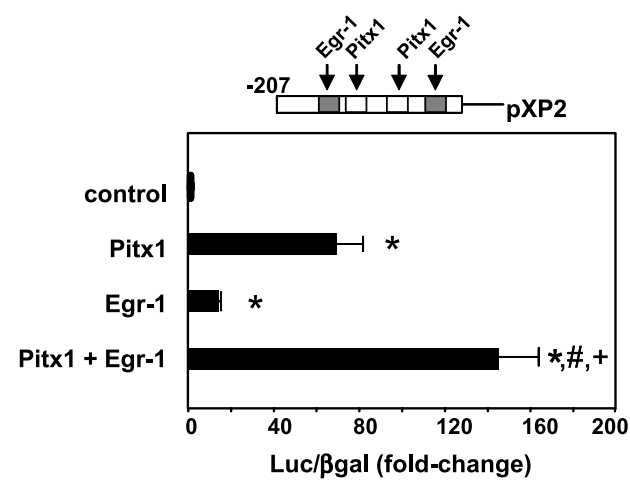

B

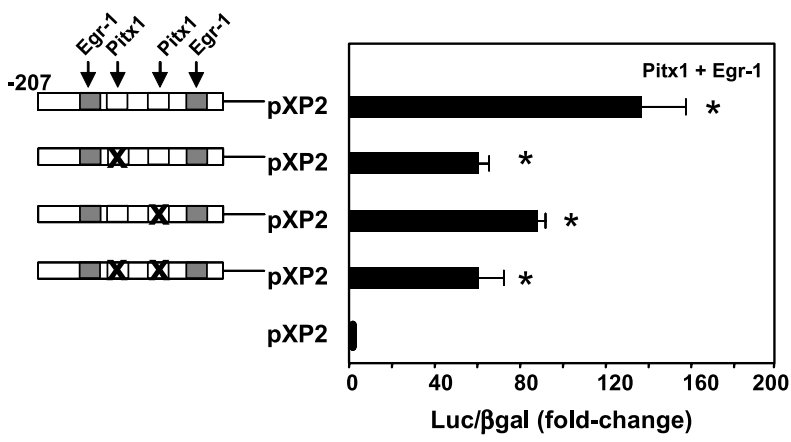

C

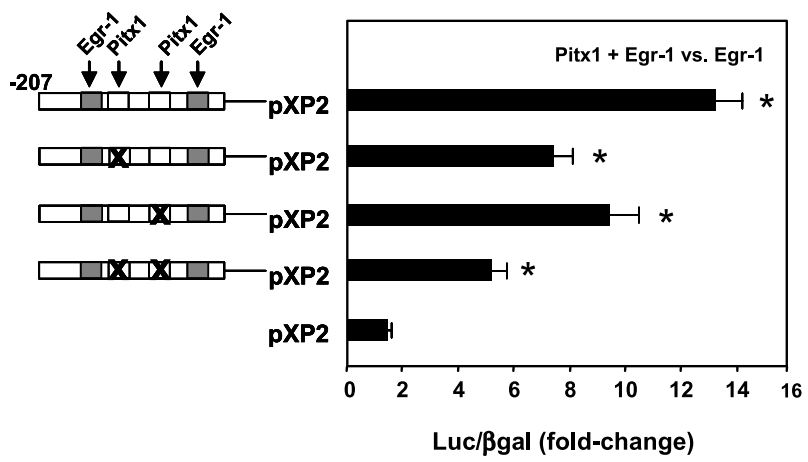

Figure 10 Effect of mutation of the Pitx1 sites on Pitx1-Egr-1 synergy. CV-1 cells were transiently transfected with the $-207 /+5 \mathrm{LH} \beta$ gene promoter present as wild-type or with mutation in the $5^{\prime}$ Pitx 1 cis-element, $3^{\prime}$ Pitx1B cis-element, or both. Cells were co-transfected with the Pitx1 and/or Egr-1 expression vectors, as indicated. (A) Response of the wild-type rat $\mathrm{LH} \beta$ gene promoter to Pitx1, Egr-1, or both transcription factors. Promoter activity calculated as fold-change over expression in the control wells which received 'empty' expression vector. ${ }^{*} P<0.001$ versus control, $\# P<0.01$ versus Pitx1 alone, $+P<0.001$ versus Egr-1 alone. (B) Analysis of Pitx1-Egr-1 synergy. Results shown as corrected luciferase activity in the presence of both the Pitx1 and Egr-1 expression vectors relative to luciferase activity with addition of the control expression vector. ${ }^{\star} P<0.005$ versus response in $\mathrm{pXP} 2$. (C) $\mathrm{LH} \beta$ gene promoter activity in response to Pitx1 and Egr-1 together relative to addition of Egr-1 alone. ${ }^{\star} P<0.005$ for the response to Pitx1+Egr-1 versus response to Egr-1 alone. synergy with the transcription factors SF-1 and Egr-1 (Tremblay et al. 1998, Tremblay \& Drouin 1999, Quirk et al. 2001). While previously believed to occur through a single Pitxl DNA-regulatory site located at position -101 in the rat LH $\beta$ gene promoter, we now present data that identify the presence of a second functional Pitxl cis-element in this gene.

Our data confirmed the ability of SF-1 and Pitxl to act independently and in synergy to stimulate LH $\beta$ transcription in both gonadotrope (L $\beta \mathrm{T} 2$ ) and fibroblast (CV-1) cell lines (Fig. 1). Furthermore, we were able to demonstrate the ability of endogenous Pitxl from gonadotrope cell lines ( $\alpha \mathrm{T} 3-1$ and L $\beta$ T2) to bind to the previously defined Pitxl site (Fig. 3). However, we were intrigued to observe a significant residual Pitxl response following mutation or deletion of the -101 (5'Pitxl) cis-element (Fig. 2). This response did not appear to be due to a cryptic site within the reporter vector, $\mathrm{pXP} 2$, as it persisted in a second reporter vector, pGL3. We therefore analyzed the LH $\beta$ gene promoter sequence and identified three potential Pitxl cis-elements (Fig. 4). One of these sites, which we call the 3'Pitx1B cis-element, was determined to bind Pitxl on EMSA (Figs. 5 and 6). In transfection analysis, mutation of the 3'Pitx 1B site significantly blunted Pitx1 responsiveness and, in conjunction with mutation of the $5^{\prime}$ Pitxl site, eliminated the Pitxl response (Fig. 7A). Our data also suggested a possible role of site A within the $3^{\prime}$ region, based on $5^{\prime}$ deletion studies, although EMSA results were less conclusive. Nevertheless, it is possible that both sequences in the $3^{\prime}$ region act cooperatively to confer Pitxl responses.

We also analyzed the functional interaction between SF-1 and Pitx1. Mutation of the 5'Pitxl site markedly blunted synergistic effects by these transcription factors (Figs. 7B and C). Mutation of the $3^{\prime}$ Pitx1B site alone did not impact the degree to which Pitxl was able to augment the SF-1 response although mutation of this site further decreased the residual Pitx1-SF-1 synergy observed with an isolated 5'Pitx 1 mutation. On EMSA, following the addition of Pitxl and SF-1 to the 5'Pitx 1-SF-1 region, we were able to detect formation of a larger complex consistent with simultaneous binding by both of these factors (Fig. 9A). In contrast, this larger complex was not detectable on the $3^{\prime}$ region probe (Fig. 9C). We propose that Pitx 1 competes with SF-1 for binding to the $3^{\prime}$ region, with the proportion of SF- 1 to Pitxl binding dependent on relative expression levels, relative affinity, or possibly activation by ligand in the case of SF-1. Pitxl bound to the $3^{\prime}$ region could potentially interact with SF-1 bound to the $5^{\prime} \mathrm{SF}-1$ cis-element, but our data suggest that the $3^{\prime}$ Pitxl site plays a relatively small role in providing synergy with SF-1 (Figs. 7B and C). Based on these functional and binding data, we conclude that Pitx 1-SF-1 synergy is dependent on Pitxl DNA binding in the rat LH $\beta$ gene. 
It should be noted that we have been unable to definitively detect binding by endogenous Pitxl from L $\beta$ T2 nuclear extracts on the $3^{\prime}$ region despite the use of a variety of nuclear extraction and EMSA protocols. While we were able to detect binding to the $5^{\prime}$ site (Fig. 3), these data required relatively large amounts of nuclear extract and prolonged exposure times. As the $3^{\prime}$ region has lower affinity than the $5^{\prime}$ site (Fig. 5), we believe that our inability to detect endogenous Pitx 1 binding to the $3^{\prime}$ region is due to a lack of assay sensitivity, rather than a reflection of inability of Pitx 1 to bind to this region. There is precedent for the presence of low affinity, but functionally important, Pitx 1 cis-elements in other gonadotrope-specific genes, including the GnRH receptor gene as reported by Jeong and coworkers (2004).

In our studies of the rat LH $\beta$ gene promoter, the $3^{\prime}$ Pitxl region contributed little to the synergistic response to Pitxl-SF-1 (Fig. 7B); however, functional interaction was lost with mutation of both putative Pitx 1 regions. In contrast, mutation of the $3^{\prime}$ region clearly blunted the Pitx1-Egr-1 interaction, although neither site was absolutely required for synergy between these two factors (Fig. 10). Mutation of the 5'Pitxl cis-element alone blunted the response to either pair of transcription factors. Thus, our data clearly suggest that the $5^{\prime}$ and 3' Pitxl regions differ in terms of Pitxl binding affinity as well as importance for interaction with other transcription factors.

Tremblay and colleagues have evaluated Pitxl effects on the bovine LH $\beta$ gene promoter (Tremblay et al. 1998, 1999). They reported that synergy between Pitxl and SF-1 was maintained, although diminished, despite mutation in the $5^{\prime} \mathrm{Pitx} 1$ site. Of note, the bovine gene lacks an obvious Pitxl consensus site in the $3^{\prime}$ region identified in the rat promoter. As a result, this persistent response cannot be attributed to an analogous secondary Pitxl site in this species. Tremblay et al. next demonstrated direct protein-protein interaction between the C-terminus of Pitx 1 and the N-terminus of SF-1 and postulated that physical interaction between these two proteins unmasks SF-1 activity by mimicking the effect of a still unidentified SF-1 ligand. They concluded that Pitx1-SF-1 synergy can occur in the absence of Pitxl DNA binding in the bovine promoter, a molecular mechanism which does not appear to exist for Pitx1-SF-1 in the rat gene. Zakaria et al. (2002) have described a similar activating pathway that is independent of Pitxl DNA binding in the rat FSH $\beta$ gene.

Precedent exists for species-specific regulation of the LH $\beta$ gene. For example, the bovine LH $\beta$ gene $5^{\prime}$ flanking region contains an NF-Y cis-element that is critical for mediating basal expression in this species, but is absent in the rat promoter. Conversely, the rat LH $\beta$ promoter sequence contains an $\mathrm{Spl}$ region which is lacking in the corresponding bovine sequence (Keri et al. 2000).

The presence of multiple Pitxl cis-elements appears to be a common theme. For example, the salmon LH $\beta$ gene promoter contains two Pitxl DNA-regulatory regions (neither clearly analogous to the mammalian regions): (1) a proximal cis-element which interacts with SF-1 and the estrogen receptor and confers a small degree of GnRH-responsiveness, and (2) a complex distal region with at least four Pitxl sites which contribute to basal and GnRH-induced expression (Melamed et al. 2002). Of interest, Pitxl is not required for GnRH expression in either the rat or bovine LH $\beta$ genes (Quirk et al. 2001 and data not shown).

The importance of Pitxl for gonadotrope development and gene expression has been underscored by the generation of both Pitxl transgenic and Pitxl-null mouse models (Szeto et al. 1999, Quirk et al. 2001). In animals null for Pitxl expression, analysis from embryonic day 15.5 through postpartum day 0 demonstrated markedly blunted expression of LH $\beta$, FSH $\beta$, TSH $\beta$ and $\alpha$-subunit due to both a decrease in the number of gonadotropes and thyrotropes as well as a decrease in transcript levels per cell. Quirk et al. (2001) generated mice harboring the bovine LH $\beta$ gene promoter upstream of a chloramphenicol acetyltransferase (CAT) reporter. CAT activity was undetectable in all lines containing a mutation in the bovine LH $\beta-5^{\prime}$ Pitx 1 site. These data do not formally eliminate the possibility of a second Pitxl site; however, they clearly suggest that activation of additional DNAregulatory elements is unable to compensate for loss of this site. As discussed above, Pitxl-mediated stimulation of LH $\beta$ gene expression also may differ between species. Therefore, it would ultimately be of interest to generate transgenic mice containing rat $\mathrm{LH} \beta$ promoter sequences.

Elimination of Pitxl protein expression in the knockout animals was less disruptive on pituitary function than mutation of the LH $\beta 5^{\prime}$ Pitxl site (Szeto et al. 1999, Quirk et al. 2001). These results suggest that other transcription factors may be assuming the role of Pitxl on this promoter. As one possibility, Rosenberg \& Mellon (2002) have demonstrated the presence of an as-yet-unidentified Otx-related protein present in immortalized gonadotrope cells which binds to the 5 'Pitxl region and directs expression to mature gonadotropes. If identified, it would be important to test this factor for functional activity on the rat LH $\beta 3{ }^{\prime} \mathrm{Pitx} 1$ cis-element.

In conclusion, a wide array of in vivo and in vitro data point to a critical role for Pitx 1 in pituitary development and gene expression. We have identified a second functional Pitxl cis-element in the rat LH $\beta$ gene promoter which contributes to Pitxl responsiveness. These results further our understanding of the molecular 
mechanisms which regulate expression of this critical reproductive gene.

\section{Acknowledgements}

We thank Ursula Kaiser for her generosity in providing the Pitxl reagents used in these studies. This work was supported by R01 HD38089 (C D H, QJ, and L M H) and a Lalor Foundation Research Fellowship Grant $(\mathrm{K}-\mathrm{H} \mathrm{J})$. The authors declare that there is no conflict of interest that would prejudice the impartiality of this scientific work.

\section{References}

deWet JR, Wood KV, DeLuca M, Helinski DR \& Subramani S 1987 Firefly luciferase gene: structure and expression in mammalian cells. Molecular and Cellular Biology 7 725-737.

Dorn C, Ou Q, Svaren J, Crawford PA \& Sadovsky Y 1999 Activation of luteinizing hormone beta gene by gonadotropin-releasing hormone requires the synergy of early growth response-1 and steroidogenic factor-1. Fournal of Biological Chemistry 274 13870-13876.

Drouin J, Lamolet B, Lamonerie T, Lanctot C \& Tremblay JJ 1998 The PTX family of homeodomain transcription factors during pituitary developments. Molecular and Cellular Endocrinology 140 $31-36$.

Edlund T, Walker MD, Barr PJ \& Rutter WJ 1985 Cell specific expression of the rat insulin gene: evidence for a role of two distinct 5' flanking elements. Science 230 912-916.

Halvorson LM, Kaiser UB \& Chin WW 1996 Stimulation of luteinizing hormone beta gene promoter activity by the orphan nuclear receptor, steroidogenic factor-1. Fournal of Biological Chemistry 271 6645-6650.

Halvorson LM, Ito M, Jameson JL \& Chin WW 1998 Steroidogenic factor- 1 and early growth response protein 1 act through two composite DNA binding sites to regulate luteinizing hormone beta-subunit gene expression. Journal of Biological Chemistry $\mathbf{2 7 3}$ $14712-14720$.

Jeong KH, Chin WW \& Kaiser UB 2004 Essential role of the homeodomain for pituitary homeobox 1 activation of mouse gonadotropin-releasing hormone receptor gene expression through interactions with c-Jun and DNA. Molecular and Cellular Biology 24 6127-6139.

Kaiser UB, Sabbagh E, Chen MT, Chin WW \& Saunders BD 1998 Spl binds to the rat luteinizing hormone beta (LHbeta) gene promoter and mediates gonadotropin-releasing hormone-stimulated expression of the LHbeta subunit gene. Fournal of Biological Chemistry 273 12943-12951.

Kaiser UB, Halvorson LM \& Chen MT 2000 Sp1, steroidogenic factor 1 (SF-1), and early growth response protein 1 (egr-1) binding sites form a tripartite gonadotropin-releasing hormone response element in the rat luteinizing hormone-beta gene promoter: an integral role for SF-1. Molecular Endocrinology 14 1235-1245.

Keri RA \& Nilson JH 1996 A steroidogenic factor-1 binding site is required for activity of the luteinizing hormone beta subunit promoter in gonadotropes of transgenic mice. Fournal of Biological Chemistry 271 10782-10785.

Keri RA, Bachmann DJ, Behrooz A, Herr BD, Ameduri RK, Quirk CC \& Nilson JH 2000 An NF-Y binding site is important for basal, but not gonadotropin-releasing hormone-stimulated, expression of the luteinizing hormone beta subunit gene. Fournal of Biological Chemistry 275 13082-13088.
Kurotani R, Tahara S, Sanno N, Teramoto A, Mellon PL, Inoue K, Yoshimura S \& Osamura RY 1999 Expression of Pitxl in the adult rat pituitary glands and pituitary cell lines: hormone-secreting cells and folliculo-stellate cells. Cell and Tissue Research 298 55-61.

Lala DS, Rice DA \& Parker KL 1992 Steroidogenic factor I, a key regulator of steroidogenic enzyme expression, is the mouse homolog of fushi tarazu-factor I. Molecular Endocrinology 6 1249-1258.

Lamonerie T, Tremblay JJ, Lanctot C, Therrien M, Gauthier Y \& Drouin J 1996 Pitx 1, a bicoid-related homeo box transcription factor involved in transcription of the pro-opriomelanocortin gene. Genes and Development $101284-1295$.

Lanctot C, Lamolet B \& Drouin J 1997 The bicoid-related homeoprotein Pitxl defines the most anterior domain of the embryo and differentiates posterior from anterior lateral mesoderm. Development 124 2807-2817.

Lanctot C, Gauthier Y \& Drouin J 1999 Pituitary homeobox 1 (Pitxl) is differentially expressed during pituitary development. Endocrinology 140 1416-1422.

Melamed P, Koh M, Preklathan P, Bei L \& Hew C 2002 Multiple mechanisms for Pitx-1 transactivation of a luteinizing hormone beta subunit gene. Fournal of Biological Chemistry 277 26200-26207.

Nordeen S 1988 Luciferase reporter gene vectors for analysis of promoters and enhancers. Biotechniques 6 454-458.

Parker KL, Ikeda Y \& Luo X 1996 The roles of steroidogenic factor-1 in reproductive function. Steroids 61 161-165.

Quentien MH, Manfroid I, Moncet D, Gunz G, Muller M, Grino M, Enjalbert A \& Pellegrini I 2002 Pitx factors are involved in basal and hormone-regulated activity of the human prolactin promoter. Fournal of Biological Chemistry 277 44408-44416.

Quirk CC, Lozada KL, Keri RA \& Nilson JH 2001 A single Pitxl binding site is essential for activity of the LHbeta promoter in transgenic mice. Molecular Endocrinology 15 734-746.

Rosenberg SB \& Mellon PL 2002 An Otx-related homeodomain protein binds an LHbeta promoter element important for activation during gonadotrope maturation. Molecular Endocrinology 16 1280-1298.

Sambrook J, Fritsch EF \& Maniatis T 1989 Molecular Cloning: $a$ Laboratory Manual. New York: Cold Spring Harbor Press.

Szeto DP, Rodriguez-Esteban C, Ryan AK, O'Connell SM, Liu F, Kioussi C, Gleiberman AS, Izpisua-Belmonte JC \& Rosenfeld MG 1999 Role of the Bicoid-related homeodomain factor Pitxl in specifying hindlimb morphogenesis and pituitary development. Genes and Development 13484494.

Thomas P, Mellon PL, Turgeon J \& Waring DW 1996 The L beta T2 clonal gonadotrope: a model for single cell studies of endocrine cell secretion. Endocrinology 137 2979-2989.

Tremblay JJ \& Drouin J 1999 Egr-1 is a downstream effector of GnRH and synergizes by direct interaction with Pitx 1 and SF-1 to enhance luteinizing hormone beta gene transcription. Molecular and Cellular Biology 19 2567-2576.

Tremblay JJ, Lanctot G \& Drouin J 1998 The pan-pituitary activator of transcription, Pitxl (pituitary homeobox 1), acts in synergy with SF-1 and Pitl and is an upstream regulator of the Lim-homeodomain gene Lim3/Lhx3. Molecular Endocrinology 12 428-441.

Tremblay JJ, Marcil A, Gauthier Y \& Drouin J 1999 Pitx 1 regulates SF-1 activity by an interaction that mimics the role of the ligand-binding domain. EMBO fournal 18 3431-3441.

Windle JJ, Weiner RI \& Mellon PL 1990 Cell lines of the pituitary gonadotrope lineage derived by targeted oncogenesis in transgenic mice. Molecular Endocrinology 4 597-603.

Wolfe MW 1999 The equine luteinizing hormone beta-subunit promoter contains two functional steroidogenic factor- 1 response elements. Molecular Endocrinology 13 1497-1510.

Wolfe MW \& Call GB 1999 Early growth response protein 1 binds to the luteinizing hormone-beta promoter and mediates 
gonadotropin-releasing hormone-stimulated gene expression. Molecular Endocrinology 13 752-763.

Zakaria MM, Jeong KH, Lacza C \& Kaiser UB 2002 Pituitary homeobox 1 activates the rat FSHbeta (rFSHbeta) gene through both direct and indirect interactions with the rFSHbeta gene promoter. Molecular Endocrinology 16 1840-1852.
Zhao L, Bakke M \& Parker KL 2001 Pituitary-specific knockout of steroidogenic factor 1. Molecular and Cellular Endocrinology 185 $27-32$.

Received 13 May 2005

Accepted 18 May 2005 